\title{
From Modeling To Digitalization
}

\subsection{Overall Context}

In the previous chapters, we have shown that what happens in organizations (companies, administrations, etc.) is based on models from various disciplines. Business models, which represent enterprise architectures with models for products and services, organizational structure, processes, data and IT infrastructure, describe in which area a company does business, how it does this, which exchange relationships it has with partners, which technical infrastructure it is supported by, etc.

In chapter 3, we have focused on approaches and notations for the specification of business processes and thus the design and representation of operational processes. In the course of digitalization, these processes must be augmented, as far as possible and economically sensible, with information and communication technology. Both the appropriate incremental improvements of existing processes, as well as fundamental process innovations, are based on creative design accomplishments, which should lead from process models to executable systems. In this chapter we will therefore first deal with the concept and typical activities of Business Process Management. With the approach of Design Thinking, we then illuminate a methodical approach to creatively produce something new and solve complex problems. Subsequently, we put the two concepts into relationship with one another.

\subsection{Activity Bundles in Business Process Management}

\subsubsection{Overview}

In chapter 1 we have already mentioned that the design of business processes up to their execution as instances in the processing of concrete business transactions ("operational business") itself represents a process. This is often understood as a 
Figure 5.1: Activity bundles in Business Process Management

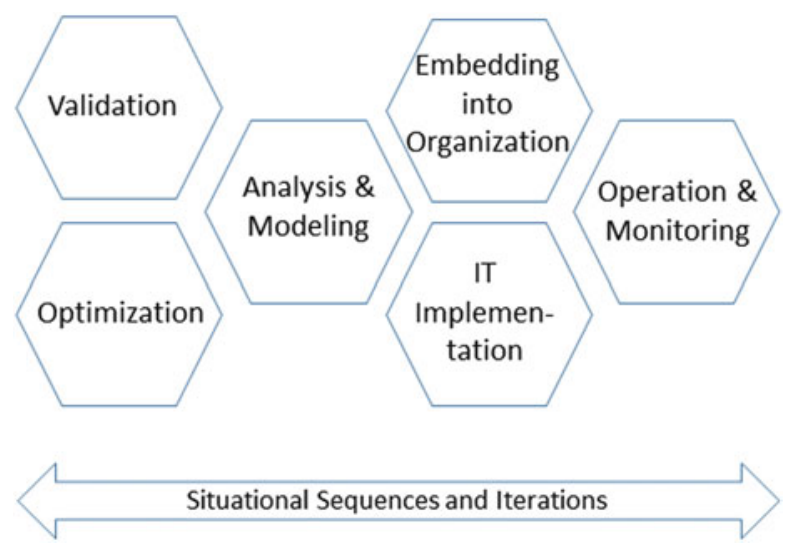

Business Process Management cycle with phases such as strategy, design, implementation and controlling [1].

In practice, however, the sub-activities are often not clearly distinguishable from each other. We therefore see them less as a circle with a sequential sequence, but rather as networked and interwoven, as the honeycomb structure in Figure 5.1 suggests. The diagram also shows that we differentiate the tasks somewhat more and identify them as bundles of activities: analysis and modeling, validation, optimization, embedding into organization, IT implementation and execution and monitoring.

Although the usual representation as a cycle suggests that in process management projects all activity bundles are run through as a sequence, their selection and sequence depend on the concrete situation, e.g., the maturity level of a process. The sections 5.2.2 to 5.2.7 explain the activities using an example process. Here, the steps are first run through completely and also in the specified sequence. Such a scenario is realistic, for example, when a process is designed for the first time or completely reorganized. In section 5.2.8, we then discuss several scenarios for improvements that can be derived from the experience gained during operation of the originally designed process environment. They illustrate the situationally different paths through the activity bundles in the further development of the process.

\subsubsection{Analysis and Modeling}

The analysis serves to gather information about why a process exists or should be implemented, which goals an organization pursues with it within the framework of its strategy, and how it is currently working. The objectives are the documentation and the acquisition of indications for improvements. The modeling uses, among other things, the results of the analysis and deals with the design of future working methods, i.e., process changes and innovations. If further information is required, the participants switch back to the analysis mode to collect it and then act again in a 
creative manner. Therefore, analysis and modeling cannot be clearly distinguished from each other. Validation and optimization also usually take place here, when the participants develop the model iteratively to the best of their knowledge and belief, taking into account the weak points identified in the analysis and trying out and discussing possible solutions.

In addition to considering determining factors such as strategic significance, objectives and risks, analysis and modeling are essentially concerned with analyzing or specifying (see also section 1.3)

- which actors (e.g., people, machines),

- perform which activities,

- according to which business rules,

- on which business objects (for example, information linked to certain carriers, physical objects),

- using which tools (e.g., IT systems) and

- how they interact in order to achieve the desired process goals and results.

For the development of process models based on these findings, the modeling languages presented in chapter 3 with the corresponding graphical notations are used.

During analysis and modeling, usually also the ground is laid for operational process controlling in the operating phase. In addition to the process attributes already mentioned, performance parameters (indicators), in particular Process Performance Indicators (PPIs), are defined, systematized in a measurement system and provided with target values [2, p. 265].Typical examples of PPIs are lead time, output per time unit, error rate, customer satisfaction, etc. The PPIs and the target values planned for them form the basis for business process monitoring, that is, operational process control during execution (see sections 5.2.7 and 7.3.3).

\section{Analysis and Modeling in a Case Study}

As a case study, we use the strongly simplified process of credit application processing in a bank. There, applications are received from interested parties for the granting of a real estate loan. Before preparing an offer, clerks check the creditworthiness of the respective customer and the value of the property to be loaned on. If the result of both checks is positive, the clerk prepares an offer with data such as loan amount, interest rate, repayment rate and term. If the loan amount is less than $€ 200,000$, he signs the offer and sends it to the customer. Otherwise, he must first obtain the approval of his department head and, in the case of more than $€ 500,000$, that of the executive board. If the creditworthiness check or the object check reveal any risks, a clerk contacts the interested party to agree on further procedures, such as reducing the loan amount. As part of an analysis of the process, this information was collected and structured (see Table 5.1). Together with additional information, this collected information serves as a basis for modeling the process. 
Table 5.1: Characteristics of the example process and information obtained for it

\begin{tabular}{l|l}
\hline $\begin{array}{l}\text { Process } \\
\text { characteristic }\end{array}$ & Result of analysis \\
\hline Actors / Roles: & $\begin{array}{l}\text { Interested party, real estate loan processing, head of real estate loan } \\
\text { department, executive board }\end{array}$ \\
\hline Activities: & $\begin{array}{l}\text { Apply for credit, check credit application (completeness), check customer } \\
\text { creditworthiness, estimate value of object to be financed, determine } \\
\text { financing conditions, Create offer, approve offer, send offer }\end{array}$ \\
\hline Business objects: & Credit application with attachments, credit offer \\
\hline Business rules: & $\begin{array}{l}\text { Credit offers over } € 200,000 \text { must be approved by the department } \\
\text { management, over €500,000 by the board. }\end{array}$ \\
\hline Interactions: & $\begin{array}{l}\text { Interested party - real estate loan processing (incoming mail), real estate loan } \\
\text { processing - head of real estate loan department, head of real estate loan } \\
\text { department - executive board, real estate loan processing - interested party }\end{array}$ \\
\hline Tools: & $\begin{array}{l}\text { Internet portal of the bank (web form), backend system of bank, workflow } \\
\text { system of bank, credit office web form, e-mail, telephone }\end{array}$ \\
\hline PPIs: & $\begin{array}{l}\text { Observation of the behavior of instances using: } \\
\text { - Processing time from the receipt of a credit application to the dispatch } \\
\text { of an offer (target: average max. 3 days), } \\
\text { - Frequency per week including distribution } \\
\text { - Rejection rate of applications by the bank } \\
\text { - Rate of rejection of offers by interested parties }\end{array}$ \\
\hline
\end{tabular}

In the case at hand we use the modeling language S-BPM described in Chapter 3 for the representation of the process, since it exists in a strongly interaction-oriented description. Generally speaking, the representation would also be possible in any other modeling language which allows the depiction of responsibilities (e.g., eEPC or BPMN)

The following figures show an excerpt of the associated process model using S-BPM. Figure 5.2 shows the subjects (agents) involved and the messages they exchange during process flow.

The communication structure (Subject Interaction Diagram, SID) does not yet contain a sequence in which the respective messages are exchanged. The sequences are described in the behavior of the subjects. Figures 5.3 and 5.4 show the behavior of the subject "interested party" and a behavior excerpt of the "real estate loan processing" subject.

The behavior of the subjects "Head of real estate loan department" and "Executive board" is described analogously. They would be involved in the process if the desired loan amount exceeded 200,000 or 500,000 euros. These cases are not modeled in Figure 5.4 - they would be represented by additional branches after the state "approval required". 


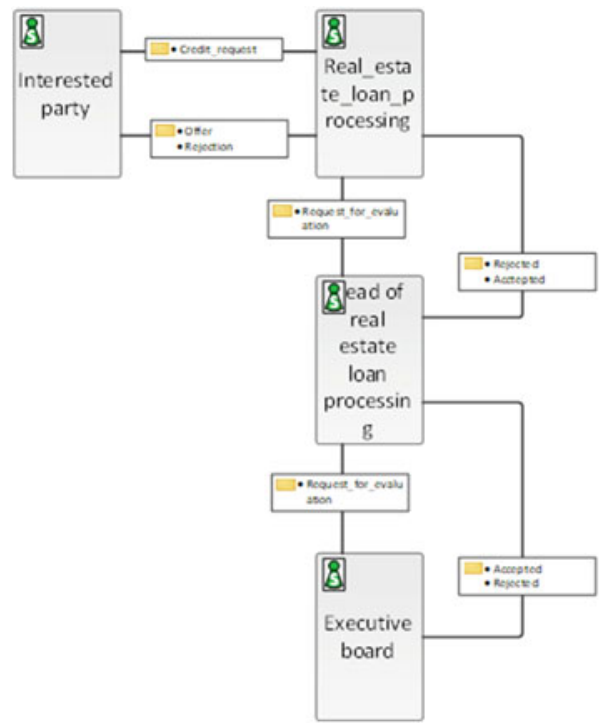

The picture shows the communication structure for applying for a loan. The communication is initiated by the subject "interested party". This subject sends the message "credit request" to the subject "real estate loan processing" and receives the messages "offer" or "rejection". According to the process requirements the other subjects exchange necessary messages. The communication structure does not yet imply a sequence in which the messages are exchanged.

Figure 5.2: Communication structure of the actors in the credit request process

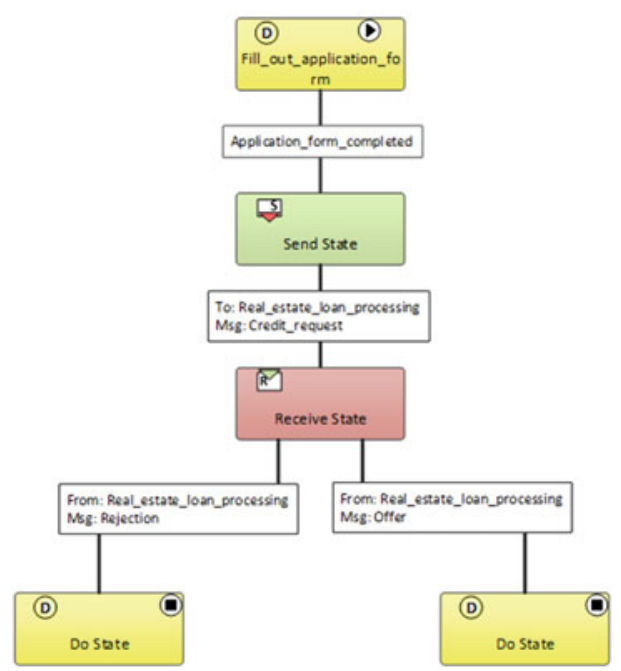

The picture shows the behaviour of the subject "interested party". A credit request is formulated in the initial state (marked by a triangle in the circle). Usually this is done by filling out a corresponding form. The contents of the form would be part of the specification of the business object "credit request". After the data object "credit request" has been created, it is sent to the subject "Real estate loan processing". Then the subject "interested party" waits for an answer. This can be either the message "Offer" or "Rejection". In both cases the subject's behaviour is terminated by reaching the respective final states which are marked as such by dots.

Figure 5.3: Behavior of the subject "interested party"

\subsubsection{Validation}

In the BPM context, validation means checking whether the designed process generates the output expected by the (external) customer and process owner, for 


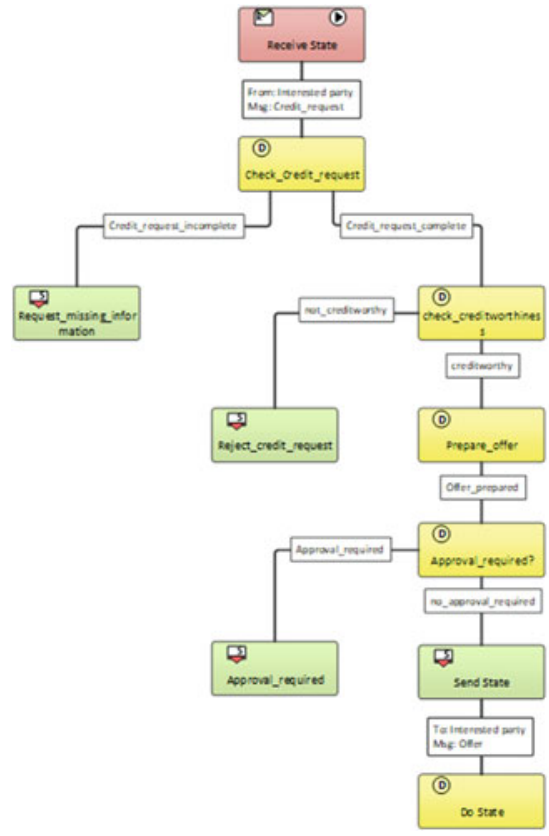

The picture shows an excerpt of the behavioral description of the subject "Real estate loan processing". This excerpt shows only the positive case. In the initial state (state marked with a triangle in a circle), the subject receives the message "Credit request" from the subject "interested party". With this message the subject receives as a payload the business object with the credit application data. In the next state it is checked whether these data are complete. If not a corresponding query message is sent to the subject "interested party". This branch (left part of the picture) is not further described in the behavior description. If the data are complete the creditworthiness of the interested party is examined. If the interested party is creditworthy an offer is provided. If the desired credit is less than 200 thousand euros, the message "Offer" is sent to the subject interested party.

Figure 5.4: Behavior of the subject "real estate loan processing"

example in the form of a service or product. This question with regards to effectiveness already refers to the results of partial steps, i.e., process participants of the own organization as customers. For example, it is necessary to evaluate whether an upstream process step provides all the information that a processor requires for a decision (for instance, approval) in his or her subtask. We have already mentioned that parts of a model are repeatedly subjected to validation, even during its step-bystep development. In addition, the object of validation is the completely finished process model, the effectiveness of which should be ensured before it is implemented in terms of Information Technology (cf., section 5.2.6). Otherwise, errors are discovered too late and lead to correspondingly high costs for their elimination.

\section{Validation in the Case Study}

The process model for the example process was validated during its development as well as at the end. In doing so, it was initially discovered that the original loan application did not include a field for the applicant's employment status and thus lacked an important risk assessment factor. This led to the extension of the business object and to a positive validation result in the corresponding iteration. 


\subsubsection{Optimization}

While validation aims at ensuring the effectiveness of business processes, optimization is about efficiency. Process efficiency can be expressed by process attributes for resource consumption such as duration and costs. Optimization means finding the optimal design of a process with regard to such process parameters. Essential starting points are improvements in operational and structural organizational design as well as IT support. Strictly speaking, optimization is not an independent activity bundle, but makes use of modeling, organizational implementation, and IT implementation (see sections 5.2.2, 5.2.5, and 5.2.6).

Simulation is a well-known method for comparing alternatives in process execution or resource allocation. It can be used to obtain quantitative information on the development of process parameters for a large number of process instances (orders, production pieces, etc.). The simulation enables the evaluation of a process model with a certain combination of parameters. These can be deterministic or stochastic quantities described by probability distributions. Through the use of parameter changes and alternative process designs, different design options can be analyzed with respect to their behavior. This allows insights to be gained into bottlenecks or inefficiencies and the sensitivity of parameters. The extension of a process model and the gathering of necessary information for conducting simulations can cause considerable effort. Attributes relevant for optimization are often interdependent and contradictory, which makes optimization difficult and requires balancing efforts. A process alternative can, for instance, have a shorter lead time relative to another, but cause higher costs. The decision for an alternative therefore also depends on the priority of the process objectives.

\section{Optimization in the Case Study}

The model could already be optimized during its design. The steps for checking customer creditworthiness and value of the property, which were initially sequentially planned, were redesigned to be executed in parallel.

\subsubsection{Embedding into an Organizational Context}

For productive operation, validated processes need to be embedded into the existing, redesigned or newly created organizational environment. This is also referred to as the organizational implementation of a process. It quite often requires an adaptation of the surrounding operational and organizational structure.

A single process is usually part of an entire value creation environment (value chain, value creation network) into which it must be seamlessly assimilated. Therefore, with regard to the operational integration into the process map, particularly the interfaces with other processes must be considered. This can lead to changes to be carried out at the interfaces of an upstream or downstream process. Such circumstances usually are already taken into account in the upstream activity bundles. Therefore, the implementation should be limited to the chronological 
coordination of the go-live procedure. This means that processes that are connected via interfaces must go live again at the same time if a change has occurred at an interface that has also made modifications necessary in the partner process.

The organizational embedding comprises the assignment of concrete actors, i.e., people as job or role holders, to the actors abstractly specified in the model. One of the challenges is the consideration of the organizational context when using workflow engines. These must be able to dissolve, for instance, dynamic surrogate regulations at runtime, as well as the fact that persons can assume different roles in the same process. For example, a superior in a vacation request process can be the approver of vacation requests for his own employees, but can also be the applicant for his own vacation, which in turn must be approved by his own superior. Therefore, the software must have organizational knowledge, facilitating the correct routing of a process instance through the processing units and steps.

Further qualitative and quantitative aspects have to be taken into account during organizational embedding. Care must be taken to ensure that the employees have the necessary qualifications (skills) to carry out the modeled behavior or can gain them through training. Adequate qualification is not only a prerequisite for successful work in the currently valid version of the process; it can also foster improvement proposals by process participants.

The number of people assigned to the abstract actors in the model influences the capacity for processing process instances and thus affects parameters such as lead time.

\section{Embedding into an Organizational Context in the Case Study}

Column 2 in table 5.2 shows the number of employees who in general are qualified to be assigned to the identified and modeled roles. The third column contains the actual capacity used (short-term absences, e.g., due to illness, are not taken into account). The heads of real estate and consumer credit departments stand in for each other, both in disciplinary and domain-specific matters. This also applies to the members of the executive board.

Table 5.2: Potential and concrete assignment of roles

\begin{tabular}{|c|c|c|}
\hline Actor/Role & $\begin{array}{l}\text { Total } \\
\text { number }\end{array}$ & $\begin{array}{l}\text { Assigned according to personnel } \\
\text { deployment plan }\end{array}$ \\
\hline Real estate loan processing & 9 & 5 full-time employees \\
\hline $\begin{array}{l}\text { Head of real estate loan } \\
\text { department }\end{array}$ & 1 & $\begin{array}{l}1 \text { manager (Head of consumer credit } \\
\text { department) } \\
1 \text { deputy }\end{array}$ \\
\hline Executive board & 3 & $\begin{array}{l}1 \text { head of private customers division } \\
1 \text { head of business customers department } \\
1 \text { head of investment management department }\end{array}$ \\
\hline
\end{tabular}




\subsubsection{IT Implementation}

Most processes cannot be carried out economically without IT support. Especially when a high degree of automation is strived for, the quality of the mapping of the process in IT becomes very important. But also, and in particular, for steps where human actors are involved (e.g., entering data, making decisions), the user-centered/ friendly design of the IT systems is of high importance.

IT-related implementation of a process means mapping it as an IT-supported workflow with integration of a suitable user interface, the execution logic and the IT systems involved. For this purpose, it is necessary first of all to transfer the more or less formal model description (see chapter 3) into a language interpretable by a workflow engine, i.e., into an executable program. This enables the engine to control the execution of a process instance at runtime according to the model. For the completion of individual subtasks during processing, a whole series of software applications and services usually have to be integrated into the process. Typical examples are ERP transactions and document and content management systems.

A relatively new approach to automation of standardized, repetitive work procedures is Robotic Process Automation (RPA). This term stands for tools that "perform [if, then, else] statements on structured data, typically using a combination of user interface interactions, or by connecting to APIs to drive client servers, mainframes or HTML code" [13]. Thus, software robots for example imitate the behavior of humans when using the graphical user interface of information systems [14]. This allows, for instance, the quick linking of heterogeneous IT systems and automated data transfer between, or data input in, various existing applications without the need for these to be modified. Artificial Intelligence and machine learning functionality promises to facilitate learning and automated adaptation of RPA tools to changes in the underlying IT systems [15].

Extensive testing of the implemented overall solutions must ensure the quality of the process support provided by IT.

\section{IT Implementation in the Case Study}

Table 5.3 shows the essential elements of the IT environment, which was designed to support the process and its sub-steps, together with their most important processrelevant functions.

\subsubsection{Operation and Monitoring}

Implemented processes go live after their approval by the responsible authorities. This means that those involved in a process execute it in the form of instances in the organizational and IT environment set up for day-to-day business.

In order to obtain information for the deliberate management of processes, it is necessary to observe their behavior during everyday operations. This monitoring records measurement data and calculates actual values for the Key Performance Indicators defined during analysis and modeling. An immediate comparison with 
Table 5.3: Realized IT environment of the process

\begin{tabular}{|c|c|}
\hline IT system/service & Selection of functions that are essential for the process \\
\hline Portal of the bank & $\begin{array}{l}\text { - Provides information material on financing and an electronic form for } \\
\text { the customer or a real estate loan officer to fill out the loan application. } \\
\text { - ... }\end{array}$ \\
\hline Workflow engine & $\begin{array}{l}\text { - Instantiates the process when the customer saves the request in the } \\
\text { portal. } \\
\text { - Controls instances according to the model, including users and other } \\
\text { systems or services as needed. } \\
\text { - Records log data for the operations. } \\
\text { - Generates messages and reports based on log data. } \\
\text { - ... }\end{array}$ \\
\hline $\begin{array}{l}\text { Backend system of } \\
\text { the bank }\end{array}$ & $\begin{array}{l}\text { - Manages customers } \\
\text { - Categorizes customers (scoring) } \\
\text { - Determines conditions } \\
\text { - Generates offers } \\
\text { - . . }\end{array}$ \\
\hline
\end{tabular}

defined target values leads to escalations along the management hierarchy and, if necessary, to short-term measures in the event of deviations. Medium- and longerterm evaluations reveal structural opportunities for improvement. The analysis of the process behavior and possible deviations allow conclusions to be drawn about causes and triggers feedback into other activity bundles.

\section{Operation and Monitoring in the Case Study}

Since the release of the process, the bank has been processing credit applications from interested parties in the described form and environment. Monitoring for the past quarter revealed the following average figures:

- Interested parties had submitted 50 applications per week.

- The bank rejected $20 \%$ of them, half of it due to lack of creditworthiness.

- For the remaining applications the interested parties received an offer within 4 days.

- In $30 \%$ of the cases the interested party accepted the offer and signed a contract.

Since competitors advertise with very short processing times, the bank assumes that the 4 days until applicants receive an offer, all other conditions being equal, is one of the reasons why customers do not sign a contract. This duration also deviates significantly from the previously formulated target of 3 days.

\subsubsection{Optimization Scenarios in the Case Study}

The following scenarios show how further analyses of the monitoring results can be used to investigate the causes of the long lead time and to branch out into suitable activity bundles for improvement measures (optimization). 
In each case, the target point of the branch-out determines the further path through the activity bundles, i.e., which subsequent activities are necessary before the redesigned process can be put into day-to-day operation. In the interests of simplification, we limit our consideration to one measure per scenario. In reality, several optimization possibilities will usually be pursued in parallel.

\section{Optimization Scenario 1}

The frequency distribution for credit application occurrence has shown that on Mondays 25, Tuesdays 15, Wednesdays 6, Thursdays 2 and Fridays also 2 applications are submitted. This could be due to the fact that interested parties view real estate, take purchasing decisions and think about financing mainly on weekends. The analysis of the dormancy period until the real estate loan department processes a request reveals a bottleneck at the beginning of the week, due to the high number of parallel applications. With the currently available capacity of 5 full-time clerks, the average dormancy period is 2 days. In order to reduce the latter and thus also the overall lead time, additional processing capacity, such as available part-time staff, could be employed on Mondays and Tuesdays. In this case, only organizational implementation in terms of staffing is concerned; the process does not change and no further activities are necessary.

\section{Optimization Scenario 2}

A more detailed analysis has shown that the high average lead time is caused by the applications with amounts between $€ 200,000$ and $€ 500,000$, because the dormancy period until the department management approves the application is very high relative to the other proportions of the total duration. This is due to the fact that the availability of department heads and surrogates for approvals is limited, e.g., due to frequent business trips.

The bank's internal process analyst proposes a change of the business rule for approval. In the future, clerks should be allowed to sign and send offers for amounts up to $€ 500,000$ themselves. This reorganization affects several bundles of activities. First of all, it requires a change in the model, as the approval loop via the department management is no longer required. The model change requires subsequent validation to ensure that the changed process (still) leads to the desired result. As part of the IT implementation, the modification of the model must also be transferred to the workflow software and tested. The omission of the approval changes the task structure of the department management. For the clerks the tasks remain the same, but competence and responsibility increase. These changes have to be taken into account in the organizational implementation, for example through updated task descriptions and possibly through the qualification of the clerks through training, e.g., for a more comprehensive risk assessment. Compared to case 1, this scenario intervenes massively in the way the process is conducted and therefore requires much more extensive activities. 


\section{Optimization Scenario 3}

The bank obtains creditworthiness data on the applicants from the associated credit bureau. For this purpose, the real estate loan processing clerks transfer the necessary customer data from the loan application to the credit bureau's web form. They then enter the results of this query into the banking system for further processing in the bank's own scoring system. The clerks give an account of the time-consuming copying of the data using copy \& paste, the errors that occur in doing so, and the resulting reworking. In order to push forward digitalization, the bank decides to use the credit bureau's web service instead of their webform-based internet information service. The web service can be integrated into the workflow in such a way that the process engine triggers it when the clerk pushes a button and transfers the customer data as parameters. The service automatically returns the result to the process engine, which then transfers it to the banking system.

In this case, the only activity bundle to be dealt with is the IT implementation, including corresponding software adaptations and subsequent tests, before going live with the modified solution. The work procedures of the participants change only slightly; qualification measures are not necessary. The elimination of manual data transfer relieves them of mindless, time-consuming, and thus cost-intensive and error-prone routine tasks. The more intensive use of IT saves processing and lead time as well as costs, while increasing customer satisfaction.

\section{Optimization Scenario 4}

In section 5.2.4, we described that the customer creditworthiness check and the property value check were deliberately parallelized during modeling in order to save lead time. The analysis showed that the bank rejects five applications per week for creditworthiness reasons. In these cases, however, clerks had already spent effort doing the parallel value check of the real estate in question. Saving on this could initially speak in favor of first checking the creditworthiness and only carrying out the value check if the result is positive. A model change with validation and adaptation of the workflow application would be necessary.

However, the sequential order would again increase the lead time and lead to a conflict of objectives. Therefore, it is important to further consider whether the effort for value checking could be reduced through automation so that unnecessary value checks no longer play a role. It is conceivable, for example, that the banking system could be enhanced with valuation functions. It could then calculate a value index after automatic transfer of parameters from the loan application (type, size, year of construction, address, etc.) and being enriched with comparative information (values from the bank's own experience and reference value tables) and geo information (infrastructure with schools, shopping facilities, transportation connections, etc.). This index would accelerate the final value estimation carried out by the clerk. With this option, the parallel execution of the steps could remain. Instead of a model change, the additional functionality in the IT implementation would have to be realized and tested, and the clerks would have to be trained in how to use the software extension. 


\subsection{Introduction to Design Thinking}

Design Thinking (DT) is a methodical approach to be creative and constructive in order to develop something new and to solve complex problems. It is characterized by innovative approaches to solution-oriented design. Problems can be better solved by focusing on the needs of the (potential) users during continuous iterations and "making comprehensible and graspable" through prototypes. This basic understanding of Design Thinking is shared by practitioners and scientists alike (for an overview of examples of definitions see [3]). The spectrum covered by the approach, on the other hand, is not seen uniformly.

There are, for example, interpretations which see it as a mind-set, as a process or as a toolbox [4]. An empirical investigation proves the perception in the continuum between the two poles of toolbox and mind-set (cf., Figure 5.5) [5].

On the one hand, this is due to the different roots, but on the other hand it is also a consequence of the inherent, constant, experience-led further development and adaptation of the concept in different contexts.

Larry Leifer, one of the protagonists of the approach at the d.school in Stanford states, that its permanent enhancements are an important part of Design Thinking, and that it would make itself unrecognizable if it were to publish a fixed manifesto one day [6].

The approach traces back to David Kelley from the design agency IDEO and professors Larry Leifer and Terry Winograd from Stanford University. In particular, the latter two recognized, when training engineering students, that the development of marketable products should focus much more on user-related aspects and less on purely technical aspects. This insight led to the development of the DT concept from the 1980s onwards and is still manifested today in the Stanford course on Mechanical Engineering 310 - Design Innovation (me310.stanford.edu). Hasso Plattner made a significant contribution to the further dissemination of this knowledge in research, academic teaching and business practice with his support of the institutions named after him at the d.school Institute of Design at Stanford University and the School of Design Thinking at Potsdam University (HPI D-School).

Due to its origin, DT was originally primarily concerned with the development of physical products. However, it is now used in a wide variety of areas, such as the development of services or entire business models, and is increasingly gaining in importance in organizational design and Business Process Management.

\subsubsection{Core Elements}

Core elements are a mixture of mindset, procedures and concrete facilities such as work areas. This is reflected in the rough division into the three "Ps", namely into the areas people, process and place.

Design Thinking begins with the creation of deep empathy for those affected by a (problem) situation. It identifies the optimal solution in the overlapping area of human desires (human-psychological aspect), feasibility (technological aspect) and 

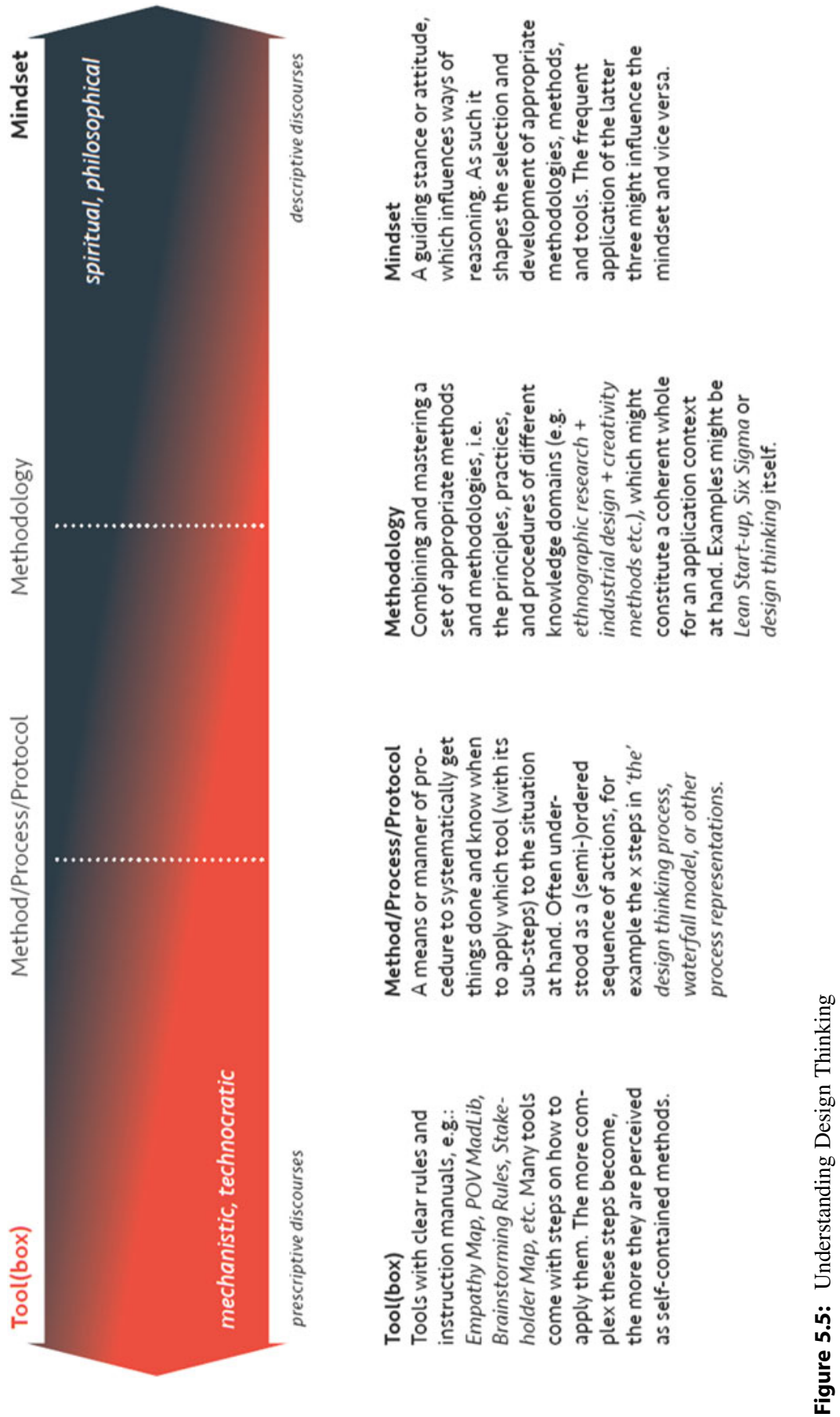
profitability (business aspect) [7]. The innovation to be developed should be something,

- that people really like (desirability),

- that is feasible from a technological and process-related point of view (feasibility), and

- that is successful from an economic point of view (viability).

To achieve this, an interdisciplinary team (people) on variable, creativitypromoting premises (place) goes through a procedure (process) with many iterations, whereas a variety of methods can be used.

\section{People}

Focusing on the human being takes place in two respects:

On the one hand, representatives of the target group of the innovation, i.e., customers or users, with their needs are in the center of interest. Developing empathy for them, putting oneself in their position in the context under consideration, and thus gaining a deep understanding of the problem is the cornerstone for successful innovation and encompasses a large part of the process described in the "Process" subsection below.

On the other hand, Design Thinking strongly focuses on the people involved in the project as individuals and as a team. It aims for increasing the quality of results by using the diversity in interdisciplinary teams. Team members should be "T-Shaped", i.e., both experts and generalists. As experts, they are deeply rooted in their specialized field and bring in the appropriate expertise (vertical line of the T). This can also involve the professional representation of a stakeholder group (e.g., sales, production, IT). Looking at a problem from different perspectives and synthesizing know-how and experience from different domains often helps to develop new approaches to solutions. The quality as generalists is a prerequisite for changing from one's own perspective to that of other participants and for being open to cooperation at the (functional) interfaces (horizontal line of the $\mathrm{T}$, "We" thinking) [8, p. 122]. Lewrick et al. plead for interdisciplinary versus multidisciplinary teams because the former truly and collectively generate ideas and stand behind them, whereas the members of multidisciplinary teams often overestimate their own perspective when finding solutions. The latter rather leads to compromise solutions, which are not fully supported by all [8]. Ideally, an interdisciplinary team is made up heterogeneously of representatives not only from as many areas of expertise as possible, but also from different age groups, nationalities, sexes etc.

The success of a Design Thinking project is largely determined by the individual characteristics of the members of the associated team and the resulting collaborative working culture and way of thinking. The focus here is on showing high esteem and empathy for people as the starting point for all activities, both for colleagues in the team as well as for users or customers. In addition, the team members should have qualities such as the ability to cooperate, curiosity, joy of experimentation, integrative thinking and optimism. A further success factor is the guidance of the team by a 


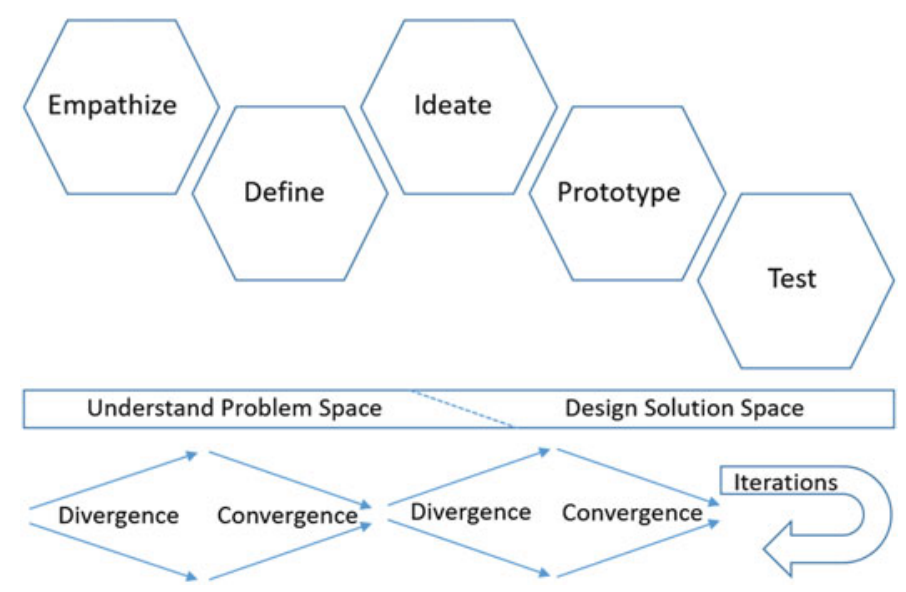

Figure 5.6: Design Thinking process according to Stanford d.school

facilitator who is experienced in the process and the use of the method. This person provides orientation for the respective phase of the process and for which instruments can best be used there without, however, intervening in terms of content.

\section{Process}

Design Thinking follows a process model with a series of steps. Although slightly different variants of the so-called microcycle with alternative names of the phases have developed over time, their content only differs marginally. We follow the model of the d.school in Stanford, which is based on five phases of the Design Thinking process, also known as working modes (cf., Fig. 5.6).

All models are characterized by the alternation between divergent and convergent viewing, thinking and acting, both in understanding the problem space and shaping the solution space. The transition between the expansion of the creative space with an everincreasing amount of information and focusing through containment is called a groan zone, i.e., a "creaking" hinge [8, p. 28f.]. Deliberate iteration is also a fundamental element in the DT process, which is expressed in the motto "fail early, fail often" or "fail forward" in an open culture allowing errors. It describes the idea that ideal solutions can only be found through multiple and early experimentation, testing and consideration of the feedback of the target group, which can lead to more or less extensive new runs of previous modes. The multiple iterations as a so-called macrocycle should lead from the understanding of the problem to the concretization of a vision for a solution and finally to an implementation plan [8, p., 37]. In all process phases the principle "Be visual \& show" applies, which means that thoughts, ideas and results are to be visually and vividly documented and presented, for example through post-its with keywords and drawings, mind maps, process maps, tangible prototypes, etc. Because of this principle it is sometimes suggested to speak of Design Doing rather than Design Thinking.

For the successful work of a team along the process, a number of rules and tips (rules of engagement) have proven to be helpful, some of which should also be 
followed in group work in general. They should be communicated at the beginning of a project and called to mind later by the facilitator if necessary:

- User-oriented way of thinking and working (development of empathy)

- No specification or limitation of ways of thinking, ways of finding solutions or fixed solutions (openness, autonomy, "Go for quantity")

- Concentration on the topic (focus), therefore no distraction by smart phones, computers, smart watches, etc. unless they are to be used deliberately, e.g., for research or prototype creation

- Active participation of each team member (own articulation, disciplined listening ("One conversation at a time") and building on ideas of others

- Encourage the development of different perspectives and wild ideas

- No value judgement during idea generation ("Defer judgement", "No killer phrases")

- Time boxing to avoid falling in love with a particular idea

The following sections briefly describe each phase together with tables including a selection of methods and tools that are used in each phase respectively. More detailed explanations can be found for example in the Bootcamp Bootleg of the $\mathrm{d}$. school [9] and in Lewrick et al. [8, p., 36].

\section{Empathize (Building Empathy)}

Empathy is the heart of a human-centered design process. To develop it means to build a deep understanding for the members of the target group with regard to the problem and its context. The aim is to understand why and how people do things, how they think about the world and what is important and useful to them, as well as to learn about their physical and emotional needs. This means observing users, listening to them, interacting with them, imagining and empathizing with their situation and thus immersing into their conscious and unconscious world of feelings, values and needs (engage, observe, immerse). This is the basic prerequisite to steer innovations in the right direction.

So-called personas are an essential instrument for documenting the learnings about the target group. Personas represent fictional customers or users together with their objectives, behavior, needs and attributes relevant for the solution to be developed.

In the model of the Hasso Plattner Institute, the "Empathize" phase encompasses the stages "Understanding" and "Observing". Table 5.4 shows common instruments for the activities included in this phase.

\section{Define (Defining Problem)}

This mode is about building on the findings from the "Empathize" mode, sharing and bringing them together, structuring, weighing and interpreting them. This synthesis serves to test and further develop the personas for ideal-type users and, if necessary, to adopt the perspectives of various stakeholders. The results are a deeper understanding of the users and the problem space as well as a more concrete, meaningful 
Table 5.4: Methods and tools for the "Empathize" phase

\begin{tabular}{|c|c|}
\hline Activity/Theme & Selected methods and tools \\
\hline $\begin{array}{l}\text { Exploit the context of the problem and } \\
\text { develop a common understanding of it }\end{array}$ & $\begin{array}{l}\text { - Brain dump } \\
\text { - Business Process and Value Maps, Concept } \\
\text { Maps, Business Model Canvas }\end{array}$ \\
\hline Structure the problem context & - Structuring/Clustering frameworks \\
\hline $\begin{array}{l}\text { Identify and understand target group (user, } \\
\text { customer) }\end{array}$ & $\begin{array}{l}\text { User Profile Canvas with } \\
\text { - Persona } \\
\text { - Jobs-to-be-done } \\
\text { - Gains \& Pains } \\
\text { - Use cases }\end{array}$ \\
\hline $\begin{array}{l}\text { Understand the target group (user, } \\
\text { customer) }\end{array}$ & $\begin{array}{l}\text { - Need-finding discussion, interview for empathy } \\
\text { (incl. preparation), e.g., with W questions (What? } \\
\text { How? Why? Who?) according to the AEIOU } \\
\text { method (Activities, Environment, Interaction, } \\
\text { Objects, User) } \\
\text { - Empathy map } \\
\text { - Future user }\end{array}$ \\
\hline
\end{tabular}

problem definition (design challenge). The latter is reflected in a single sentence which, as a so-called Point of View (POV), forms the question for the subsequent phase of idea generation [8, p. 73]. In practice, different POV questions are used. A typical formulation is the "How might we?"-question, for example, "How might we help [user, customer] to reach [a certain goal]?" [8, p. 74].

In the Hasso Plattner Institute model, "Define" corresponds to the "Define point of view" phase. Table 5.5 lists common tools for the activities included in this phase.

\section{Ideate (Finding Ideas)}

The aim of idea generation is to develop a wide range of solutions, i.e., to develop and visualize as many ideas, and as many different ideas, as possible. The starting point is the point-of-view question, however all the insights gained so far are incorporated into this phase, including user profile canvas, empathy map and customer/user experience journey. The basic instrument is brainstorming, which can be further and repeatedly stimulated by creativity techniques and specific tasks (e.g., generating ideas for certain functions). The design and testing of initial "lowfidelity" prototypes can also provide further food for thought for solutions and trigger iterations. The use of methods in this mode should enable going beyond obvious solutions, and thus increase the innovation potential by using the collective perspectives and strengths of the team. Unexpected solution directions should be able to emerge and contribute to the quantity and diversity of ideas. This results in a multitude of ideas, which are sorted, condensed and evaluated. The entire process should be strictly separated between the generation and evaluation of ideas, so as not to restrict the creative flow at an early phase.

In the Hasso Plattner Institute model, "Ideate" corresponds to the "Finding Ideas" phase. Common instruments for the activities contained in this mode are shown in Table 5.6. 
Table 5.5: Methods and tools for the "Define" phase

\begin{tabular}{|c|c|}
\hline Activity/Theme & Selected methods and tools \\
\hline Share insights & - Story share and capture (Storytelling) \\
\hline $\begin{array}{l}\text { Interpret insights, draw } \\
\text { conclusions }\end{array}$ & $\begin{array}{l}\text { - Saturate and group } \\
\text { - Empathy map } \\
\text { - Customer/User Experience Journey (with actions, } \\
\text { mindset, touch points, pain points, moments of truth) }\end{array}$ \\
\hline $\begin{array}{l}\text { Understand the target group (user, } \\
\text { customer) even better }\end{array}$ & $\begin{array}{l}\text { - Persona } \\
\text { - Composite Character Profiles } \\
\text { - Power of Ten } \\
\text { - } 2 x 2 \text { Matrix } \\
\text { - Why-How-Laddering } \\
\text { - Point of view ... } \\
\text { - 360-degree view } \\
\text { - A day in the life of ... }\end{array}$ \\
\hline
\end{tabular}

Table 5.6: Methods and tools for the "Ideate" phase

\begin{tabular}{l|l}
\hline Activity/Theme & Selected methods and tools \\
\hline $\begin{array}{l}\text { Generate ideas } \\
\text { (iteratively) }\end{array}$ & $\begin{array}{l}\text { - General brainstorming based on POV (e.g., How might we?) with } \\
\text { stimulation through creativity techniques } \\
\text { Targeted brainstorming (critical functionalities, benchmark, dark horse, } \\
\text { funky prototype) } \\
\text { - Power of Ten, Bodystorming } \\
\text { - Quick\&Dirty Prototyping }\end{array}$ \\
\hline $\begin{array}{l}\text { Sort and condense } \\
\text { ideas }\end{array}$ & $\begin{array}{l}\text { - Swap Sort, 2x2 Matrix } \\
\text { - Concept/Systems/Mind Maps, idea profiles }\end{array}$ \\
\hline $\begin{array}{l}\text { Evaluate and } \\
\text { prioritize ideas }\end{array}$ & $\bullet$ Four-category method; Post-it voting, Spend your budget \\
\hline
\end{tabular}

\section{Prototype (Creating prototypes)}

Prototyping picks up the most highly rated ideas from idea development and continues to develop them further. In doing so, the principle of Design Thinking is implemented: to visualize issues, products and results as early as possible and to test, discuss and further develop them with potential users, incorporating their feedback into tangible models. Prototypes are thus created in order to learn to clarify open questions and discrepancies, to start a conversation or a discourse and to recognize dead ends quickly and at an early stage, which in turn saves costs. In addition to the change requests, the feedback can also lead to complete rejection and thus to a fundamental iteration over more distant previous phases. This procedure is also described by the slogan "Love it, change it or leave it".

Prototyping transfers ideas from the mind into the physical world. A prototype can therefore be anything that takes on a physical form and follows the maxim "don't tell me, show me!": a wall with post-it notes, a role play, a room, an object, a storyboard or any combination of different means of expression.

The granularity of the prototype should correspond to the progress of the project. In the early stages of a project, prototypes should be created that can be made quickly 
Table 5.7: Methods and tools for the "Prototype" phase

\begin{tabular}{l|l}
\hline $\begin{array}{l}\text { Activity/ } \\
\text { Theme }\end{array}$ & Selected methods and tools \\
\hline $\begin{array}{l}\text { Create } \\
\text { prototypes }\end{array}$ & $\begin{array}{l}\text { Low-fidelity prototypes, e.g., from handcrafting material (Lego, modeling } \\
\text { clay, etc.) }\end{array}$ \\
& $\begin{array}{l}\text { Role plays, Storytelling, Storyboards } \\
\text { Wireframes, Screen-design tools } \\
\end{array}$ \\
& - Shooting and editing video
\end{tabular}

and cost-effectively (low fidelity, quick \& dirty), but already generate useful feedback from users and colleagues. In later stages, the prototypes should be refined and allow careful investigating of specific issues. They serve to deepen empathy, to test and to gain further ideas and inspiration.

In the Hasso Plattner Institute model, "Prototype" corresponds to the "Develop prototype" phase. Table 5.7 shows common tools for the activities included in this phase.

\section{Test (Testing prototypes)}

As discussed in the previous section, testing is closely linked to prototyping. The recommendation "Prototype as if you know you're right, but test as if you know you're wrong" describes the way of thinking that illustrates this relation. Testing offers the opportunity to receive qualitative feedback on the prototypical solutions, to make them better, to learn more about the users, and thus to deepen the empathy for them. The test mode is an iterative learning mode in which the prototypes are placed in the context of the potential user, then used and evaluated by him. Important principles are: "Don't talk, show!", create experiences, and enable the user to make comparisons. The feedback during the tests can lead not only to changes, but also to complete rejection and thus again to a fundamental iteration over more distant previous phases. This procedure is also described by [8, p. 34] the slogan "Love it, change it or leave it". In principle, each iteration loop, regardless of its scope, must reflect which previous results (e.g., personas, user/customer experience journey) have to be adapted as a result of the feedback.

In the Hasso Plattner Institute model, "Test" corresponds to the "testing" phase. Table 5.8 contains instruments for the activities carried out during the phase.

\section{Place}

For the work of the interdisciplinary teams in the described modes, it is necessary to create a creativity-fostering environment, so-called make or creative spaces. This applies in particular to the availability, size and furnishing of premises as well as to visualization and prototype design tools and materials. The main aim is to provide the teams with freely and permanently available work, interaction, relaxation and storage areas. Flexible furniture with castors, describable and erasable surfaces (walls, tables, boards), as well as good and fast access to information (Internet, libraries, etc.), tools, working materials and catering add to a suitable environment 
Table 5.8: Methods and tools for the "Test" phase

\begin{tabular}{l|l}
\hline Activity/Theme & Selected methods and tools \\
\hline Gather feedback & $\bullet$ Feedback grid \\
& $\begin{array}{l}\bullet \text { "I like, I wish, What if?" } \\
\bullet \text { A/B testing with digital tools }\end{array}$ \\
\hline
\end{tabular}

[7, p., 216]. Lighting, ventilation and air conditioning are also important factors to be considered.

In practice, teams are sometimes given the opportunity to design the environment themselves (e.g., build their own furniture), especially in the case of long-term projects. Doorley and Witthoft have published instructions and experiences, among other things, in the design of creative environments for the d.school [10].

\subsection{Connecting the Concepts}

\subsubsection{Overview}

As shown, Design Thinking aims at the innovation of products and services, business models and business processes. The focus is on user centricity, creativity and agility in an experimental, iterative process that interdisciplinary teams traverse.

Process management pursues a comparable objective with agile and creative process design of new, or redesign of existing, processes under consideration of customer needs.

In the following, we put the concepts into relation to one another and discuss the promising use of Design Thinking elements for process management.

We pay particular attention to the digitalization of processes, i.e., the reasonable use of information and communication technology for process improvement and innovation. Prototypes and final solutions are therefore always workflow applications with different degrees of automation.

\subsubsection{User Centricity}

During process analysis traditional BPM approaches usually involve those participating with interviews and workshops. However, the 'hard' facts of the work in the process with the characteristics listed in Chapter 5.2.2 are in the foreground of the activity-related and process-related interview questions, card techniques or observations. Aspects such as understanding users' motivation, ways of thinking, and values, which are expressly emphasized for the development of empathy in Design Thinking, are largely ignored here. Newer concepts such as Social BPM have changed little in this regard.

The Subject-oriented Business Process Modeling (S-BPM) approach, which was already used in the case study at the beginning of this chapter, can build an interesting bridge. It focuses on the subjects as actors in the process. With the 
associated methodology and language (see Section 3.6) as well as suitable tool environments, representatives of subjects involved in the process can participate in iterative solution development not only as respondents or observers, but also as active designers. They not only explicitly specify the behavior of the subject they represent and its interactions with other participants, but can also immediately test and change the result of their design by executing the resulting model. In doing so, they can implicitly bring in the 'soft' factors mentioned above.

\subsubsection{Agile Process with Iterations}

In practice, more extensive process management projects are often still carried out using traditional project management methods in clearly defined phases with milestones, comparable to the waterfall model in software development.

This means that the path from analysis of the design of the business model and its organizational and IT implementation to an executable workflow application takes an extensive amount of time. It also increases the likelihood that the resulting IT solution will deviate from the evolving needs and desires of users.

For process digitalization in particular, it is therefore advantageous to adapt the agile, iterative process of Design Thinking. This opens up the possibility of meeting the increasing dynamics with regard to the emergence of new processes and changes to existing processes, for example due to new or changed business models such as servitization. For further considerations, we compare the modes of Design Thinking with the activity bundles in process management (cf., Fig. 5.7).

Together with the explanations in sections 5.2.2. and 5.3.2 the illustration shows that DT makes a stronger distinction between problem understanding and solution design. The latter only begins with "Ideate". Before this, the actual situation is extensively illuminated and, for example, documented and visualized along the way via personas in the customer/user experience journey, before the point-ofview question is formulated as the starting point for generating ideas.

In process management, on the other hand, the problem is usually clearly formulated at the outset. When renewing existing processes, it is usually derived from the desire for improved process performance (e.g., shorter lead times). In practice, therefore, only weak points in the current state are documented and analysis information is used to develop and visualize a new target model, just like in a new process. The creative, design-related part begins earlier than with Design Thinking and tends to be underpinned by less information when being started. It is driven more analytically (e.g., by performance indicators) than by the "soft" factors identified in the course of empathy development in Design Thinking. Regardless of the somewhat different concrete design, the activity bundle Analysis \& Modeling can be assigned to the DT modes Empathize, Define and Ideate.

The use of proven DT instruments is ideal for a more comprehensive capturing of the problem context and the resulting expansion of the spectrum of solutions for process innovation. Especially when developing a new process, the team members 
BPM Activity Bundles
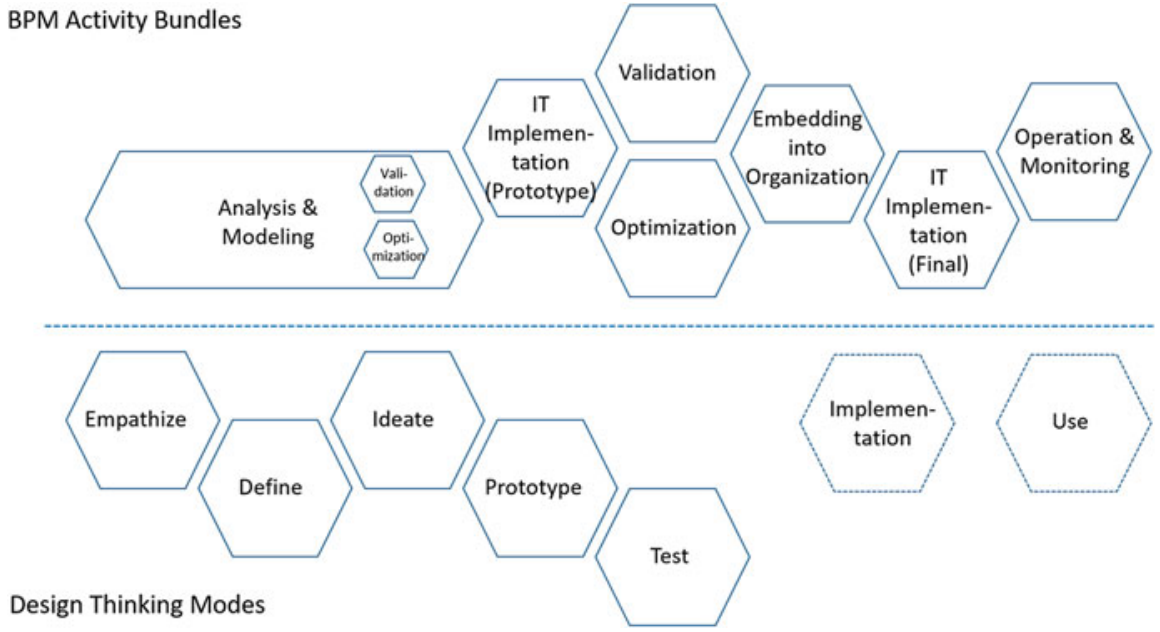

Figure 5.7: Assignment of Design Thinking modes and BPM activity bundles

can broaden their horizon and develop a common understanding with a brain dump concerning the problem environment and the discussion of the results.

With the help of personas for the process participants in their respective roles as well as interviews and observations, customer/user experience journeys can be described.

If participants in the process are team members themselves, they can also visualize their own experiences as journeys. This extends the information base beyond the classic, objective process characteristics to include the user's perspective. This broader foundation for the development of solution ideas should justify the higher effort.

In section 5.2.2 we had explained that effectiveness and efficiency, at least of model excerpts, are already taken into account during the analysis and modeling of processes. This is especially true if the future users do this themselves, as in subject orientation. Therefore, the activity bundles Validation and Optimization are assigned to the DT-mode Test, but also cover Empathize, Define and Ideate.

With the focus on process digitalization, the DT Prototype mode corresponds to the activity bundle IT implementation in process management. Prototyping in Design Thinking makes the claim to producing a prototype quickly and with simple means, i.e., cost-effectively, in order to quickly obtain feedback from the user (Test mode) and to utilize it. By applying this "fail early, fail often" principle to process management, the team must be able to create an executable model with minimal effort. The focus is therefore on creating a functional prototype in the form of software that allows users to experience what their work with the IT solution would look like. However, assigning the prototype to the IT implementation should not mean that programming is necessary. Rather, it must be possible in the interests of rapid iterations to generate a prototype automatically from the model and have it tested by the users in the activity bundle validation. In the same way, subsequent 
model changes based on feedback again lead to a new prototype, until a version is found that satisfies the users. Such low-cost and early prototyping possibly prevents more complex reworking during the later realization of the real runtime environment. Using a comparable approach, the user interface can be designed according to the principles of user experience design.

Since the respective process model is not only the basis for prototypes, but in its ultimately adopted version also for the workflow application strived for, the activity bundle IT implementation includes also their realization in the way described in section 5.2.6. If software which goes beyond the model-based workflow control has to be developed for this purpose, SCRUM as a user-centered, agile software development method serves as a good choice. In the context of IT implementation, it is also important to decide to what extent the strategy of minimum viable products, often used by software start-ups, should be pursued. This would mean making software with minimal functionality available to customers or users not only prototypically, but also productively in order to obtain their feedback for further development. This could be risky with IT solutions for business-critical processes; on the other hand, it could possibly give an edge over competitors by familiarizing customers with features at an early stage.

As explained in sections 5.2.5 and 5.2.7, the model must also be embedded into the organization (Organizational Embedding) before the process can go live (Operation \& Monitoring).

In Design Thinking, comparable steps follow for the implementation, for example, of a product on the basis of an accepted prototype as well as for its use. However, these steps no longer belong to the modes in the narrower sense (dotted forms in Fig. 5.7).

\section{Conclusion}

In order to meet the requirements of digitalizing processes, a process management approach should combine Design Thinking and process management concepts.

It must be suitable for quickly mapping processes and their changes both (business) domain-related and in IT, while at the same time adequately involving the users in short iteration cycles in order to approximate the resulting solution to their ideas.

In addition to the instruments that can be used for the Design Thinking modes Empathize, Define and Ideate, easy-to-handle methods and tools are particularly necessary for this purpose, with which the team and/or the process participants themselves are able to:

1) articulate their individually different mental models of work

2) harmonize these different mental models

3) develop ideas for solutions and concrete proposals for solutions in the form of models

4) automatically convert these models into executable prototypes and test them

5) transfer released models to live workflow applications with limited effort 
An example of a concept to support 1) and 2) is Compare/WP (see chapter 6.1.2). Requirements 3), 4) and 5) are, for example, covered by the S-BPM approach and BPM tools based on it $[11,12]$.

\subsubsection{Interdisciplinary Team}

The importance of the interdisciplinarity of the facilitator-led team in Design Thinking was explained in section 5.3.2.

BPM projects are also usually carried out by teams. We distinguish thereby between four roles:

- Governors set the determining factors for the project. These essentially comprise the scope, i.e., the delimitation of the process system worked on in the project, as well as the methodology and tools, specifically related to analysis and modeling.

- Actors are the present or future actors who carry out the actions in the runtime instances of the process to be changed or developed. They are therefore the carriers of concrete execution-related process knowledge for their part in the creation of the process result, i.e., they know which sub-steps they carry out in which order, which information and tools they need for this and with whom they interact.

- Experts support the other roles with methodical and domain-related knowledge. They are, for example, domain experts (specialists) who have expertise in the relevant field that goes beyond that of the actors, and which they can contribute as such. Method experts help the participants, especially the actors, to articulate and harmonize their mental models and to implement them with one of the modeling languages presented in Chapter 3. Finally, IT experts are called in for the technical implementation of the business process models. If required, experts in the various fields from outside the company's own organization are also involved as external consultants.

- Facilitators moderate and coordinate the approach and the cooperation of the participants. For example, they ensure that actors coordinate the interfaces between their work steps and, if necessary, identify and involve suitable experts for particular problems. In the course of all this, facilitators motivate involved people to act compliantly in accordance with the determining factors set by governors and monitor their behavior respectively.

With the traditional phase-oriented approach in BPM, usually a project leader as a facilitator coordinates the collaboration of domain and method specialists as actors and experts during analysis, modeling, validation and optimization.

The implementation of the approved business process models is then carried out by IT experts. In section 5.4.3., we have already identified long duration and the resulting deviation from the stakeholders' needs as probable disadvantages of this approach. 
For some time now, the BizDevOps approach, which is intended to take into account the increasing agility requirements in the course of digitalization, has been becoming more widespread. It strives for a comparatively closer integration of the business departments (business, biz), IT development units (development) and IT operation units (operations) ${ }^{1}$. Right from the start, the agile team includes representatives from all areas in the roles described, who jointly design the process solution. The concept can thus both improve business and IT alignment and also foster enabling through IT. The former means that the degree of coverage of the business departments' needs increases through appropriate IT services. In enabling, IT gives impetus to the use of information and communication technology for business model and business process innovations.

Like Design Thinking, the BizDevOps approach therefore involves an interdisciplinary team. The challenge in such teams is to establish the "We" thinking among "T-shaped" individuals. This is due to the fact that line units from which the participants originate (various business departments involved in the process, IT development, IT operations) pursue different goals and often tend to give them a higher priority than a goal to be achieved jointly (innovative or improved process solution). In addition, creativity may be hampered by the involvement of domain experts. On the one hand, process participants are often aware of weak points in existing processes and ways for improvement. On the other hand, they may be 'operationally blind' and too restricted in their consideration of the problem space and, in particular, the solution space. Recruitment should therefore not only take into account diversity aspects such as gender, age and cultural background. Rather, a meaningful balance needs to be found between domain experts and team members who have a background in other fields and have no strong self-interest in the appearance of a solution. The shift in emphasis can be made dependent on whether the goal is more a process improvement in which the experiences and inputs of those familiar with the existing process can be helpful. If, on the other hand, the focus is on a more radical process innovation, this could possibly have a limiting effect. Of course, even with the original objective of improvement, ideas for a fundamental innovation of the process under consideration should not be ignored.

\section{References}

1. Allweyer, T. (2009). Business process management: Strategie, Entwurf, Implementierung, Controlling, W3L, Herdecke

2. Schmelzer, H., \& Sesselmann, W. (2013). Geschäftsprozessmanagement in der Praxis Kunden zufriedenstellen, Produktivität steigern, Wert erhöhen, 8. Auflage, Munich, Carl Hanser.

3. Schallmo D. R. (2017). Design thinking erfolgreich anwenden. Springer Gabler.

\footnotetext{
${ }^{1}$ When looking beyond company boundaries, one could add partners in the value creation network such as suppliers, customers or logistics service providers (Network Partners) and speak of NetBizDevOps.
} 
4. Brenner, W., et al. (2016). Design thinking as mindset, process and toolbox. In W. Brenner \& F. Uebernickel (Eds.), Design thinking for innovation (pp. 3-21). Cham: Springer.

5. Schmiedgen, J., Rhinow, H., Köppen, E., \& Meinel, C. (2015). Parts without a whole? The current state of design thinking practice in organizations. Technische Berichte des HassoPlattner-Instituts für Softwaresystemtechnik an der Universität Potsdam Nr. 97, Univ.-Verl., Potsdam.

6. Leifer, L. (2012). Über design thinking, bad guys, experimente, Jagd und organisationalen Wandel. In: Organisations Entwicklung, Nr. 2, 2012, pp. 8-13.

7. Uebernickel, F., Brenner, W., Pukall, B., Naef, T., \& Schindlholzer, B. (2015). Design thinking - Das handbuch. Frankfurt am Main: Frankfurter Allgemeine Buch.

8. Lewrick, M., Link, P., \& Leifer, L. (Eds.). (2017). Das design thinking playbook - Das handbuch. München: Vahlen.

9. Last access on May 1, 2018, from https://dschool.stanford.edu/resources/design-thinkingbootleg

10. Doorley, S., \& Witthoft, S. (2012). Make space: How to set the stage for creative collaboration. Hoboken, NJ: Wiley.

11. Fleischmann, A., Schmidt, W., \& Stary, C. (2013). Subject-oriented BPM = Socially executable BPM. In Proceedings of the 15th IEEE Conference on Business Informatics (CBI 2013) (pp. 399-406). Vienna: IEEE Computer Society.

12. Fleischmann, A., Borgert, S., Elstermann, M., Krenn, F., \& Singer, R. (2017). An overview of S-BPM-oriented tool suites. Proceedings of the 9th S-BPM ONE, Darmstadt.

13. Tornbohm, C., \& Dunie, R. (2017). Market guide for robotic process automation software. Gartner Report G00319864, Stamford.

14. Geyer-Klingeberg, J., Nakladal, N., Baldauf, F., \& Veit, F. (2018). Process mining and robotic process automation: A perfect match. In F. Casati et al. (Eds.), Proceedings of the Dissertation Award, Demonstration, and Industrial Track at BPM 2018. Last access on May 2, 2019, from http://ceur-ws.org/Vol-2196/BPM_2018_paper_28.pdf

15. van der Aalst, W., Bichler, M., \& Heinzl, A. (2018). Robotic process automation. Business \& Information Systems Engineering, 60, 269-272. https://doi.org/10.1007/s12599-018-0542-4.

Open Access This chapter is licensed under the terms of the Creative Commons Attribution 4.0 International License (http://creativecommons.org/licenses/by/4.0/), which permits use, sharing, adaptation, distribution and reproduction in any medium or format, as long as you give appropriate credit to the original author(s) and the source, provide a link to the Creative Commons licence and indicate if changes were made.

The images or other third party material in this chapter are included in the chapter's Creative Commons licence, unless indicated otherwise in a credit line to the material. If material is not included in the chapter's Creative Commons licence and your intended use is not permitted by statutory regulation or exceeds the permitted use, you will need to obtain permission directly from the copyright holder. 